\title{
The Amsterdam Declaration on Essential Surgical Care
}

\author{
Matthijs Botman $^{1} \cdot$ Rinse J. Meester $^{1} \cdot$ Roeland Voorhoeve $^{1} \cdot$ Henning Mothes $^{2} \cdot$ \\ Jaymie A. Henry ${ }^{3} \cdot$ Michael H. Cotton ${ }^{3}$ - Robert H. S. Lane ${ }^{4} \cdot$ Pankaj G. Jani ${ }^{5}$. \\ Hugo A. Heij ${ }^{1}$ Edna Adan Ismail ${ }^{6}$
}

Published online: 10 April 2015

(C) Société Internationale de Chirurgie 2015

\section{Introduction}

On behalf of the supporting organisations and all participants of the international symposium 'Surgery in Low Resource Settings', November 2014, in Amsterdam, we present the 'Amsterdam Declaration on Essential Surgical Care'.

The situation with regard to a lack of surgical capacity in LMICs is untenable, and urgent action is required to alleviate the situation. Many thousands of patients are dying unnecessarily every day because there is no one trained to operate on them. As a consequence, the death toll of surgical conditions in low resource settings currently outnumbers the death toll of HIV, malaria and TB combined.

Rarely has there been such unanimity in the field of global surgery, and there is urgent action needed.

The lack of surgical care will be on the agenda during the World Health Assembly in May 2015. We solicit international health policy makers to support the initiative towards a WHA resolution on 'Strengthening Emergency and Essential Surgical Care and Anaesthesia as a component of Universal Health Coverage'.

We need to make the world realize that we completely forgot something: Surgery should be part of the United Na-

Matthijs Botman and Rinse Meester contributed equally to this work.

Matthijs Botman

matthijsbotman@gmail.com

1 Netherlands Society for International Surgery, Amsterdam, The Netherlands

2 German Society for Tropical Surgery, Homburg, Germany

3 International Collaboration for Essential Surgery, New York, USA

4 International Federation of Surgical Colleges, London, UK

5 COSECSA, Nairobi, Kenya

6 Lancet Commission on Global Surgery, Bellagio, Italy 
tions' post-2015 sustainable development goals as an essential and named component of universal health coverage.

\section{The Amsterdam Declaration on Essential Surgical Care}

Being concerned about the fact that:

- Two billion people have no access to essential surgical care $^{1}$ especially in low- and middle-income countries

\footnotetext{
1 Definition:

We define essential surgical care as 'Basic surgical procedures that save lives and prevent permanent disability or life-threatening complications. Such surgery should be of appropriate quality and safety, accessible at all times and affordable to the community'

Proposed list of 15 essential surgical conditions
}

\begin{tabular}{|c|c|}
\hline Conditions & Interventions \\
\hline Obstructed labour & $\begin{array}{l}\text { Caesarean section. } \\
\text { Symphysiotomy, assisted } \\
\text { or manipulative delivery }\end{array}$ \\
\hline Severe uterine bleeding & $\begin{array}{l}\text { Evacuation of retained } \\
\text { products of the Placenta, } \\
\text { B-lynch suture, repair of } \\
\text { uterine perforation }\end{array}$ \\
\hline Surgical infections & $\begin{array}{l}\text { Incision and drainage of } \\
\text { abscess, fasciotomy, dental } \\
\text { extraction, tympanotomy, } \\
\text { bone drilling, arthrotomy }\end{array}$ \\
\hline $\begin{array}{l}\text { Severe wounds (including } \\
\text { burns) }\end{array}$ & $\begin{array}{l}\text { Debridement, hemostasis, } \\
\text { suturing, escharotomy, skin } \\
\text { grafting }\end{array}$ \\
\hline Severe head injury & $\begin{array}{l}\text { Management of head injury, } \\
\text { cranial burr holes, } \\
\text { elevation of depressed skul } \\
\text { fracture }\end{array}$ \\
\hline Airway obstruction & $\begin{array}{l}\text { Management of } \\
\text { compromised airway, } \\
\text { tracheostomy, } \\
\text { cricothyroidotomy, } \\
\text { removal of foreign body }\end{array}$ \\
\hline $\begin{array}{l}\text { Chest injury and } \\
\text { infections }\end{array}$ & $\begin{array}{l}\text { Intercostal drainage, } \\
\text { thoracostomy }\end{array}$ \\
\hline Acute Abdomen & $\begin{array}{l}\text { Emergency laparotomy } \\
\text { including appendicectomy }\end{array}$ \\
\hline $\begin{array}{l}\text { Fractures and } \\
\text { Dislocations }\end{array}$ & $\begin{array}{l}\text { Reduction of fractures and } \\
\text { dislocations, casting and } \\
\text { splinting, external fixation }\end{array}$ \\
\hline $\begin{array}{l}\text { Severe limb ischemia, } \\
\text { sepsis and injury }\end{array}$ & Amputations \\
\hline $\begin{array}{l}\text { Urinary outflow } \\
\text { obstruction }\end{array}$ & Suprapubic catheterization \\
\hline Hernia & Hernia repair \\
\hline Cataract & $\begin{array}{l}\text { Cataract extraction and Intra- } \\
\text { ocular lens insertion }\end{array}$ \\
\hline Clubfoot & $\begin{array}{l}\text { Casting and splinting, } \\
\text { tenotomy }\end{array}$ \\
\hline Simple cleft lip & Cleft lip repair \\
\hline
\end{tabular}

- Five million people die from injuries every year; more than $90 \%$ of whom are found in low-resource settings

- A third of a million women die every year from childbirth; $15-20 \%$ of whom can be saved through safe essential surgical care

- Two million women live with untreated obstetric fistula; all entirely in low-resource settings

- Twenty million people suffer from treatable blindness caused by cataract

- Millions of people suffer from correctable congenital deformities such as cleft lip and clubfoot

- Surgical conditions now kill more people than HIV, TB and Malaria combined

- Surgical and obstetric conditions approximately account for $11 \%$ of the world's disability-adjusted life years (DALYs) lost each year

- There is a critical shortage in surgically and anaesthetically trained health care workers in low- and middle-income countries (for example, 0.5 surgeon per 100.000 people in Sub Saharan Africa)

- The medical infrastructure, supplies and observed procedures in low- and middle-income countries are insufficient to provide the needed essential surgical care

Taking into account that:

- At present there is limited global effort from a public health perspective to reduce the number of deaths and disabilities in low- and middle-income countries caused by surgical conditions

- Essential surgical care in low-resource settings is cost effective in DALYs and cost competitive to other preventive health measures

- Making essential surgical care available in lowresource settings requires a multilevel approach

We make the following declaration ${ }^{2}$ :

- We solicit the support of the governments of all nations, the UN, the WHO, the World Bank,

\footnotetext{
2 This Declaration was initiated during the final session of the symposium 'Surgery in Low Resource Settings' on November 15th, 2014 in Amsterdam with the following organisations represented: AMREF flying doctors, the Association of Surgeons of Great Britain and Ireland, the College of Surgeons of East, Central and Southern Africa (COSECSA), CAPACARE, Doctors Without Borders (MSFHolland), Edna Adan University Hospital, Emergency, the German Society for Tropical Surgery (DTC), the G4 Alliance, the International Collaboration for Essential Surgery (ICES), the International Committee of the Red Cross (ICRC), the International Federation for Rural Surgery (IFRS), the International Federation of Surgical Colleges (IFSC), Mercy Ships, the Netherlands Society for International Surgery (NSIS), the Netherlands Society for Plastic Surgery (NVPC), Volonteers OverSeas (VSO) and the World Orthopedic Concern (WOC).
} 
institutional donors as well as other major donors, nongovernmental organisations, all involved medical and surgical societies, colleges and professional bodies.

To ensure that:

Essential surgery be made available to all regardless of age, gender, race, ethnic group, geographical location, financial status, and political and religious affiliation through the following actions:

1. Incorporate essential surgical care as part of national health services within universal health coverage (UHC)

2. Realign and increase the allocation of resources to improve essential surgical care delivery
3. Make training accessible to health workers providing essential surgical care

4. Ensure the provision of supplies, equipment, and infrastructure for safe, essential surgical care

5. Develop protocols for ethical surgical practice, assessment, audit and follow-up

6. Optimise collaboration amongst all stakeholders such as professional organisations, institutions, charities and funding agencies to avoid duplication and maximise efforts to promote essential surgical care

7. Support the proposed World Health Assembly resolution 'Strengthening emergency and essential surgical care and anaesthesia as a component of universal health coverage' in May 2015 
This declaration is supported by:
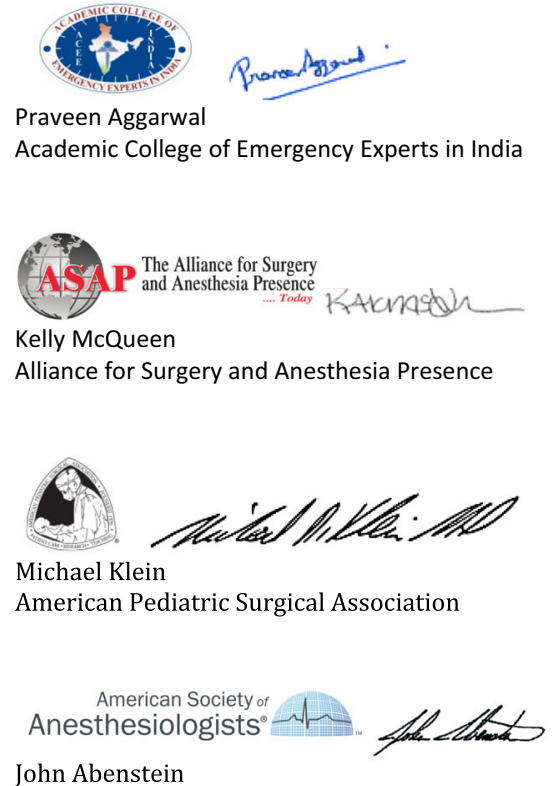

John Abenstein

American Society of Anesthesiologists

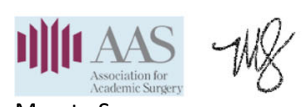

Mamta Swaroop

Association for Academic Surgery

$$
\text { AORN drimtare }
$$

Linda Groah

Association of periOperative Registered Nurses
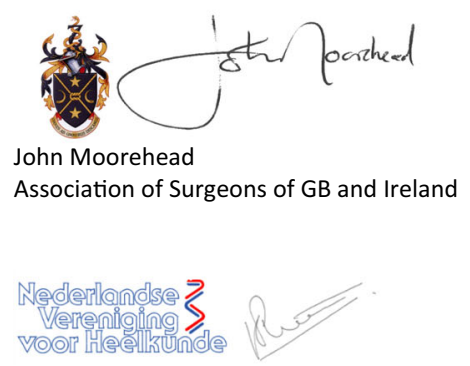

Robert Pierik

Association of Surgeons of the Netherlands

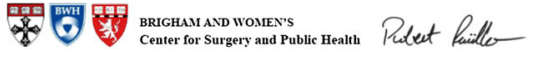

Robert Riviello

Center for Surgery and Public Health, Brigham and Women's Hospital

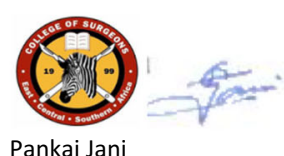

Pankaj Jani

College of Surgeons of East, Central and Southern Africa

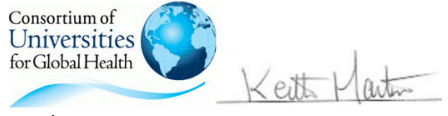

Keith Martin

Consortium of Universities for Global Health

\section{diamedica Robert Neightour}

Robert Neighbour

Diamedica

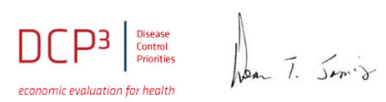

Dean Jamison

Disease Control Priorities 3th Edition

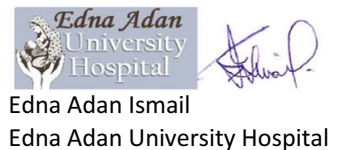

\section{$\bigoplus_{\text {EMERGENCY }}$}

Gino Strada

Emergency

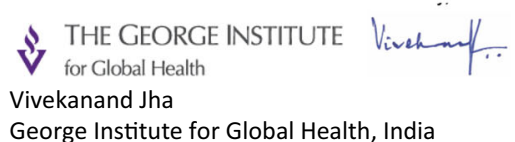


<smiles>CC1C2CO[C@H]1C2</smiles>

Henning Mothes

German Society for Tropical Surgery

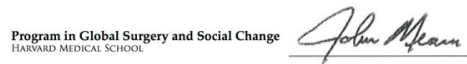

John Meara

Global Surgery and Social Change, Harvard Medical School
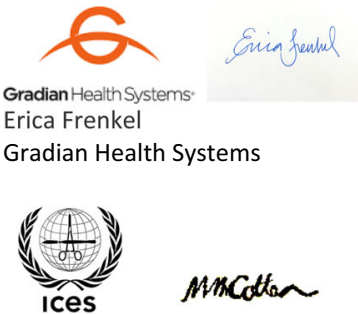

Mrcottan

Michael Cotton

International Collaboration for Essential Surgery
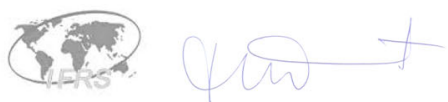

Peter Reemst

International Federation for Rural Surgery

\section{(4)}

녀 는

(7) Ruslane

Robert Lane

International Federation of Surgical Colleges

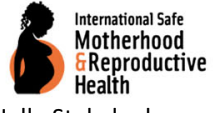

Jelle Stekelenburg

International Safe Motherhood and Reproductive Health

\section{O) Jhpiego

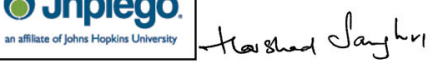 \\ Harshad Sanghvi \\ Jhpiego Corporation}

\section{A \\ JOHNS HOPKINS phior Antullal \\ an Abdullah \\ Johns Hopkins Global Surgery Initiative}

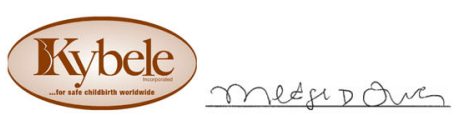

Medge Owen

Kybele, Inc.

\section{lifebox Puncithth \\ Saving Iives through sate \\ Lifebox Foundation}

\section{TRQiE}

Wouter Bakker

Medical Doctors in International Health and Tropical Medicine Netherlands (TROIE)

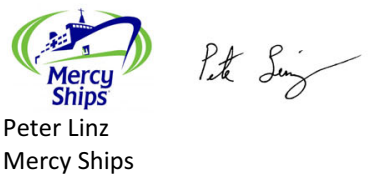

Netherlands Orthopedic Association<smiles>[Mg]C1C=CC=C1</smiles>

Ankie van den Broek

Netherlands Society for International Health and Tropical Medicine (NVTG)

NETHERLANDS SOCIETY
FOR INTERNATIONAL SURGERY Plomber

Roeland Voorhoeve

Netherlands Society for International Surgery 


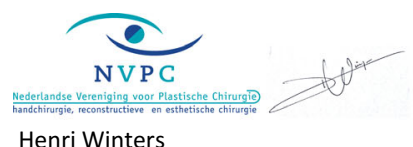

enri Winters

Netherlands Society for Plastic Surgery

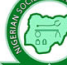

Elisabeth Ogboli-Nwasor

Nigerian Society of Anaesthetists

Operation Smile

Ruben Ayala

Operation Smile

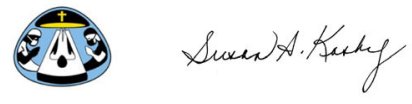

Susan Koshy

Pan-African Academy of Christian Surgeons

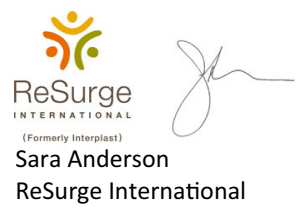

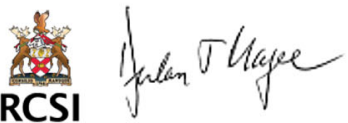

Declan Magee

Royal College of Surgeons in Ireland

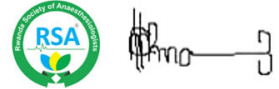

Rosemaru Mukunzi

Rwanda Society of Anaesthesiologists

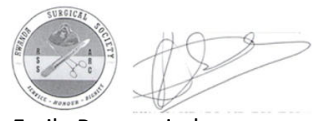

Emile Rwamasirabo

Rwanda Surgical Society

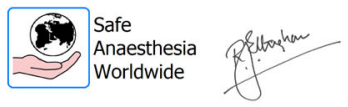

Roger Eltringham

Safe Anaesthesia Worldwide sama HOPE Shivuni tray Patel

Shivani Garg Patel

Samahope

$\int S$ Smile Train Srin Stieber

Erin Stieber

SmileTrain

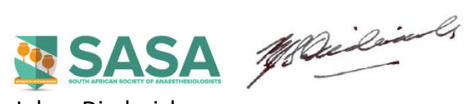

Johan Diedericks

South African Society of Anaesthesiologists

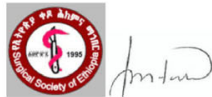

Miliard Derbew

Surgical Society of Ethiopia
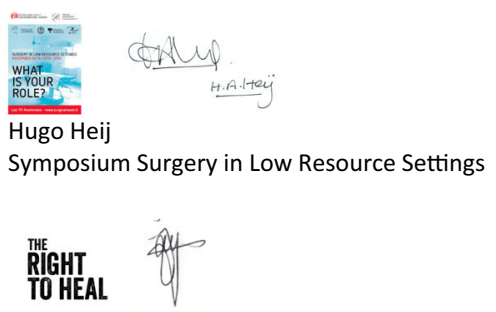

Jaymie Henry

The Right to Heal

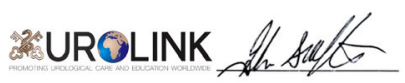

John McGrath

Urolink, British Association of Urological Surgeons

190 An/elenent

Joris Eekhout

Voluntary Service Overseas

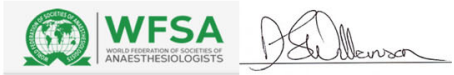

David Wilkinson

World Federation of Societies of Anaesthesiologists

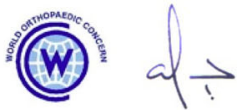

Antoon Schlosser and Michael Laurence

World Orthopedic Concern 